frequencies of inflammatory diseases in families of patient with FMF haven't been investigated.

Objectives: In this study, we have aimed to evaluate the comorbid disorders in a large cohort of families of patients with FMF.

Methods: Four hundred and ninety-eight children with FMF, one hundred and forty patients with JIA and ninety-two healthy children were interviewed between December 2019 and January 2020. In JIA group and healthy control group, patients who have family history for FMF were excluded from the study. Patients were asked about characteristics of their disease attacks and if there is a relative with any inflammatory diseases who does not have FMF in patient's $1^{\text {st }}$ and 2 th degree relatives.

Results: Demographic features of study group have shown in Table 1. The most common MEFV mutations in patients with FMF were: M694V homozygotes (13.2\%), M694V heterozygotes (12\%), M694V homozygotes and R202Q homozygotes (6,8 \%). Type II diabetes, asthma and hypothyroidism were the most commonly detected diseases in all cohorts. Frequency of Behçet's disease, allergic rhinitis and type II diabetes were significantly higher in families of patients with FMF than other groups $(p<0.05)$ (Table 2).

Table 1. Demographic features of study population.

\begin{tabular}{|c|c|c|c|}
\hline & FMF $t$ & JIA $t+$ & Healthy Control \\
\hline & $\begin{array}{c}\mathrm{n}: 498(\%) \\
\text { mean +/- SD }\end{array}$ & $\begin{array}{c}\text { n: } 140(\%) \\
\text { mean } \\
\text { +/- SD }\end{array}$ & $\begin{array}{c}\mathrm{n}: 92(\%) \\
\text { mean +/- SD }\end{array}$ \\
\hline Female & $284(57)$ & $91(65)$ & $55(59.8)$ \\
\hline Age (years) & $12.9 \pm 8.2$ & $11.7 \pm 5.1$ & $7.4 \pm 4.6$ \\
\hline Age at Onset (years) & $4.3 \pm 3.3$ & $5.4 \pm 4.1$ & - \\
\hline Age at Diagnosis (years) & $6.3 \pm 3.6$ & $6.3 \pm 4.5$ & - \\
\hline Delay in Diagnosis (months) & $23.8 \pm 29.2$ & $11.3 \pm 28.2$ & - \\
\hline Follow-up Duration (years) & $6.9 \pm 8.3$ & $5.3 \pm 4.0$ & - \\
\hline Consanguinity & $100(20)$ & $25(17.8)$ & $8(8.6)$ \\
\hline Family History of FMF & $282(56.6)$ & $0(0)$ & $0(0)$ \\
\hline JIA subgroup & - & & - \\
\hline Oligoarticular & & $72(51.4)$ & \\
\hline Polyarticular (RF negative) & & $16(11.4)$ & \\
\hline Polyarticular (RF positive) & & $3(2.1)$ & \\
\hline Enthesitis Related Arthritis & & $14(10)$ & \\
\hline Psoriatic Arthritis & & $7(5)$ & \\
\hline Systemic & & $23(16.4)$ & \\
\hline Other & & $5(3.5)$ & \\
\hline Clinical Findings & & - & - \\
\hline Fever & $392(78.1)$ & & \\
\hline Abdominal Pain & $429(86.1)$ & & \\
\hline Chest Pain & $102(20.5)$ & & \\
\hline Arthralgia & $334(67.1)$ & & \\
\hline Arthritis & $157(31.5)$ & & \\
\hline Extremity Pain & $64(12.8)$ & & \\
\hline Heel Pain & $44(8.8)$ & & \\
\hline Myalgia & $43(8.6)$ & & \\
\hline${ }^{\star} E L E$ & $13(2.6)$ & & \\
\hline Serositis & $10(2)$ & & \\
\hline
\end{tabular}

†Familial Mediterranean Fever $+†$ Juvenile Idiopathic Arthritis *Erysipelas like erythema

Table 2. Comparison of frequencies of diseases detected among families of patient groups (shortened).

\begin{tabular}{lcccc}
\hline Diseases & FMF & JIA & Healthy Control & $\mathrm{p}^{1}$ \\
\hline Type II Diabetes & $284(57)$ & $64(45.7)$ & $44(47.8)$ & $\mathbf{0 . 0 2}$ \\
Asthma & $139(27.9)$ & $30(21.4)$ & $20(21.7)$ & 0.19 \\
Hypothyroidism & $122(24.4)$ & $27(19.2)$ & $14(15.2)$ & 0.09 \\
Eczema & $68(13.6)$ & $14(10)$ & $5(5.4)$ & 0.06 \\
Psoriasis & $49(9.8)$ & $6(4.2)$ & $7(7.6)$ & 0.10 \\
Allergic Rhinitis & $49(9.8)$ & $3(2.1)$ & $1(1)$ & $\mathbf{0 . 0 0 1}$ \\
Hyperthyroidism & $40(8)$ & $9(6.4)$ & $3(3.2)$ & 0.24 \\
Behçet's Disease & $31(6.2)$ & $1(1)$ & $2(2.1)$ & 0.01 \\
Rheumatic Fever & $30(6)$ & $10(7.1)$ & $2(2.1)$ & 0.25 \\
\hline
\end{tabular}

Conclusion: In this study, we have reported increased frequencies of Behçet's disease, allergic rhinitis and type II diabetes in families of patients with FMF. Our results suggest that possible increased mutation load among families of patients with FMF may cause increased inflammatory diseases.

References:

[1] Yildiz M, Adrovic A, Tasdemir E, et al. Evaluation of co-existing diseases in children with familial Mediterranean fever. Rheumatol Int. 2020;40(1):57-64. doi:10.1007/s00296-019-04391-9

Disclosure of Interests: None declared

DOI: 10.1136/annrheumdis-2020-eular.6263

\section{FRI0456 \\ EARLY IMPLEMENTATION OF TREATMENT WITH ETANERCEPT INCREASES THE LIKELIHOOD TO ACHIEVE REMISSION}

J. Klotsche ${ }^{\star 1}$, G. Horneff ${ }^{2}$, P. Haas ${ }^{3}$, I. Foeldvari ${ }^{4}$, M. Niewerth ${ }^{5}$, K. Minden ${ }^{5}$. ${ }^{1}$ German Rheumatism Research Center, Berlin, Germany; ${ }^{2}$ Asklepios Clinic Sankt Augustin, Sankt Augustin, Germany; ${ }^{3}$ German Center for Pediatric and Adolescent Rheumatology, Garmisch-Partenkirchen, Germany;

${ }^{4}$ Hamburg Centre for Pediatric and Adolescence Rheumatology, Hamburg, Germany; ${ }^{5}$ German Rheumatism Research Center, Berlin, Germany

Background: Juvenile idiopathic arthritis (JIA) is the most common chronic inflammatory rheumatic disease in children and adolescents. A consistent therapy is required to avoid consequential damage and permanent loss of function. Biologic disease modifying anti-rheumatic drugs (bDMARDs) provide a well-accepted option for treatment of patients with a severe course of JIA. Etanercept (ETA) is still the most commonly prescribed bDMARD for JIA in Germany.

Objectives: To analyze adherence to treatment with ETA with special attention on discontinuation after achieving an inactive disease and recurrence of active disease after ETA withdrawal.

Methods: Data from two ongoing prospective, multicenter, non-interventional registries BiKeR and JuMBO were used for the analysis. JuMBO is the follow-up study to BiKeR and follows patients who have reached the age of 18 . Both registers provide treatment data, individual trajectories of clinical data and outcomes from childhood into adulthood in JIA patients treated with bDMARDs and csDMARDs. Clinical disease characteristics, such as disease activity, were reported by the rheumatologists in addition to patient-reported outcomes at each six-months follow-up. Remission was defined as inactive disease defined by the Wallace Criteria (1).

Results: Data from 2,500 patients who were included in BiKeR and had an age $\geq 18$ at the time of analysis were considered. A subset of 1,535 were enrolled in JuMBO. The mean follow-up was 8.6 (SD 4.2) years for the JuMBO patients. The majority of them had polyarthritis $(35 \%)$, followed by enthesitis-related arthritis (20\%). A total of $1,779(68.8 \%$ of 2,584$)$ patients were ever treated with ETA, providing 2,178 ETA treatment courses. There were 1,724 (67\%) patients with first, 338 patients with a second and 54 with a third course of ETA treatment course. $710(41.2 \%)$ discontinued ETA by ineffectiveness in the first course with similar rates of discontinuation due to ineffectiveness in the first and second course. $A$ total of 332 (+/-MTX, 19.3\%) discontinued ETA after achieving remission in the first ETA course. Among those, 129 (38.9\%) patients did not require treatment with any other bDMARD subsequently until last follow-up (3.9 years, SD 3.5), while $169(50.9 \%)$ re-started treatment with ETA, 14 (4.2\%) with adalimumab and 4 with other bDMARDs. The likelihood of discontinuing ETA due to an inactive disease was positively associated with a younger age (hazard ratio (HR) 1.08 $p<0.001$ ), persistent oligoarthritis (HR 1.89, $p=0.004)$, a shorter duration between JIA onset and ETA start (HR 1.10, p<0.001) as well as a good response to therapy within the first six months of treatment (HR 1.11, p<0.001). 209 (of 332) had ETA monotherapy at withdrawal. Of those, $77 \%(n=161)$ experienced recurrence of disease with a mean time to flare of 12.1 (SD 13.7) months. 129 patients restarted bDMARD therapy ( $n=117$ ETA). We could not identify any correlates for the risk of flare. $70 \%$ re-achieved remission and $20 \%$ again discontinued therapy thereafter. Conclusion: The study confirms the good effectiveness of ETA, even in the re-treatment of patients with JIA. Our data highlight the association of an early bDMARD treatment with a higher likelihood to achieve an inactive disease indicating a window of opportunity.

\section{References:}

[1] Wallace CA, Giannini EH, Huang B et al. American College of Rheumatology provisional criteria for defining clinical inactive disease in select categories of juvenile idiopathic arthritis. Arthritis Care Res 2011;63:929-36

Disclosure of Interests: Jens Klotsche: None declared, Gerd Horneff Grant/ research support from: AbbVie, Chugai, Merck Sharp \& Dohme, Novartis, Pfizer, Roche, Speakers bureau: AbbVie, Bayer, Chugai, Merck Sharp \& Dohme, Novartis, Pfizer, Roche, Peter Haas: None declared, Ivan Foeldvari Consultant of: Novartis, Martina Niewerth: None declared, Kirsten Minden Consultant of: GlaxoSmithKline, Sanofi, Speakers bureau: Roche DOI: 10.1136/annrheumdis-2020-eular.4088

\section{FRI0457 2 LONG-TERM OUTCOMES AND TREATMENT EFFICACY IN PATIENTS WITH TNF RECEPTOR-ASSOCIATED AUTOINFLAMMATORY SYNDROME (TRAPS) FROM THE EUROFEVER INTERNATIONAL REGISTRY}

R. Papa ${ }^{1}$, T. Lane ${ }^{2}$, F. Bovis ${ }^{3}$, K. Minden ${ }^{4}$, I. Touitou ${ }^{5}$, L. Cantarini ${ }^{6}$, M. Cattalini ${ }^{7}$ L. Obici ${ }^{8}$, A. Jansson ${ }^{9}$, A. Belot ${ }^{10}$, B. Woska-Kuśnierz ${ }^{11}$, R. Berendes ${ }^{12}$

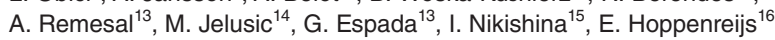


M. C. Maggio ${ }^{17}$, T. Youngstein ${ }^{2}$, T. Rezk ${ }^{2}$, C. Papadopoulou ${ }^{18}$, P. Brogan ${ }^{18}$, P. N. Hawkins ${ }^{2}$, P. Woo ${ }^{18}$, N. Ruperto ${ }^{1}$, M. Gattorno ${ }^{19}$, H. J. Lachmann ${ }^{2}$ ${ }^{1}$ IRCCS Istituto Giannina Gaslini, Clinica Pediatrica e Reumatologia, Genova, Italy; ${ }^{2}$ University College London Medical School, Royal Free Hospital Campus, National Amyloidosis Centre, London, Italy; ${ }^{3}$ University of Genoa, Department of Health Science, Genova, Italy; ${ }^{4}$ Charite University Hospital Berlin, Berlin, Germany; ${ }^{5}$ Hôpital Arnaud de Villeneuve, Montpellier, France; ${ }^{6}$ Policlinico le Scotte, University of Siena, Rheumatology Unit, Siena, Italy; ${ }^{7}$ Spedali Civili, Universita' di Brescia, Clinica Pediatrica, Brescia, Italy; ${ }^{8}$ Fondazione IRCCS Policlinico San Matteo, Pavia, Italy; ${ }^{9}$ Dr. von Haunersches Kinderspital, Muenchen, Germany; ${ }^{10} \mathrm{Hopital}$ Femme Mère Enfant, Groupement Hospitalier Est, Lyon, France; ${ }^{11}$ Children's Memorial Health Institute, Warsaw, Poland; ${ }^{12}$ Kinderkrankenhaus St. Marien, Landshut, Germany; ${ }^{13}$ Hospital Universitario La Paz, Madrid, Spain; ${ }^{14}$ University Hospital Centre Zagreb, University School of Medicine, Zagreb, Croatia; ${ }^{15}$ A. Nasonova Research Institute of Rheumatology, Moscow, Russian Federation; ${ }^{16}$ Radboud UMC, Nijmegen, Netherlands; ${ }^{17}$ Ospedale dei Bambini, Palermo, Italy; ${ }^{18} \mathrm{UCL}$ Great Ormond Street Institute of Child Health, London, United Kingdom; ${ }^{19}$ IRCCS Istituto Giannina Gaslini, Centre for Autoinflammatory Diseases and Immunodeficiencies, Genova, Italy

Background: Tumour necrosis factor (TNF) receptor-associated periodic syndrome (TRAPS) is one of the best-known monogenic auto-inflammatory disorders resulting from an autosomal dominant variation in the TNF super family receptor 1A (TNFRSF1A) gene (1).

Objectives: To define best treatment approach in patients with TRAPS and effect on long-term outcomes.

Methods: We reviewed all data on patients with TRAPS enrolled in the Eurofever international registry according the INSAID gene variant classification and the new Eurofever/PRINTO classification criteria (EPCC).

Results: Data on 226 patients were available. Patients not fulfilling the EPCC carrying likely benign/benign variants (21 patients, $9 \%$ ) or VOUS/not classified variants (40 patients, $18 \%$ ) displayed a milder disease than the patients fulfilling the EPCC with VOUS/not classified variants (38 patients, 17\%) or pathogenic/ likely pathogenic variants (127 patients, $56 \%$ ). In particular, in patients not fulfilling the EPCC, less frequent abdominal pain and skin rashes, higher efficacy rate of colchicine and no development of AA amyloidosis have been reported. Almost $90 \%$ of patients fulfilling the EPCC required maintenance therapy and anti-interleukin (IL)-1 drugs were the most frequently used, with the highest efficacy rate (>85\% complete response), while Etanercept was less effectively used and discontinued in $65 \%$ of patients.

Conclusion: Anti-IL-1 drugs are the best maintenance treatment in TRAPS with potential to reverse the most serious disease complications of AA amyloidosis and infertility. The diagnosis of TRAPS should be considered very carefully in patients carrying VOUS/not classified variants not fulfilling the EPCC.

References:

[1] Lachmann HJ, Papa R, Gerhold K, Obici L, Touitou I, Cantarini L, et al. The phenotype of TNF receptor-associated autoinflammatory syndrome (TRAPS) at presentation: a series of 158 cases from the Eurofever/EUROTRAPS international registry. Annals of the rheumatic diseases 2014;73:2160-7.

Acknowledgments: RP would like to thank the European Federation of Immunology (EFIS) for the short-term bursary and HL for her continuous support and guidance during the fellowship at the National Amyloidosis Centre in London. Disclosure of Interests: Riccardo Papa: None declared, Thirusha Lane: None declared, Francesca Bovis: None declared, Kirsten Minden Consultant of: GlaxoSmithKline, Sanofi, Speakers bureau: Roche, Isabelle Touitou: None declared, Luca Cantarini: None declared, Marco Cattalini: None declared, Laura Obici: None declared, Annette Jansson: None declared, Alexander Belot: None declared, Beata Woska-Kuśnierz: None declared, Rainer Berendes: None declared, Agustin Remesal: None declared, Marija Jelusic: None declared, Graciela Espada: None declared, Irina Nikishina: None declared, Esther Hoppenreijs: None declared, Maria Cristina Maggio: None declared, Taryn Youngstein: None declared, Tamer Rezk: None declared, Charalampia Papadopoulou: None declared, Paul Brogan Grant/research support from: Roche, Novartis, SOBI, Chemocentryx, Novimmune, Consultant of: Roche, SOBI, UCB, Novartis, Speakers bureau: Roche, SOBI, UCB, Novartis, Philip N Hawkins: None declared, Patricia Woo: None declared, Nicolino Ruperto Grant/research support from: Bristol-Myers Squibb, Eli Lily, F Hoffmann-La Roche, GlaxoSmithKline, Janssen, Novartis, Pfizer, Sobi (paid to institution), Consultant of: Ablynx, AbbVie, AstraZeneca-Medimmune, Biogen, Boehringer Ingelheim, Bristol-Myers Squibb, Eli Lily, EMD Serono, GlaxoSmithKline, Hoffmann-La Roche, Janssen, Merck, Novartis, Pfizer, R-Pharma, Sanofi, Servier, Sinergie, Sobi, Takeda, Speakers bureau: Ablynx, AbbVie, AstraZeneca-Medimmune, Biogen, Boehringer Ingelheim, Bristol-Myers Squibb, Eli Lily, EMD Serono, GlaxoSmithKline, Hoffmann-La Roche, Janssen, Merck, Novartis, Pfizer, R-Pharma, Sanofi, Servier, Sinergie,
Sobi, Takeda, Marco Gattorno Consultant of: Sobi, Novartis, Speakers bureau: Sobi, Novartis, Helen J. Lachmann: None declared

DOI: 10.1136/annrheumdis-2020-eular.4496

\section{\begin{tabular}{|l|l}
\hline FRI0458 & EFFICACY AND SAFETY OF PCV13 VACCINATION IN
\end{tabular} JIA PATIENTS WITH SYSTEMIC MANIFESTATIONS ON TOCILIZUMAB AND CANAKINUMAB TREATMENT}

D. Vankova ${ }^{1}$, E. Alexeeva ${ }^{1,2}$, T. Dvoryakovskaya ${ }^{1,2}, K^{2}$ Isaeva ${ }^{1}$,

A. Chomakhidze ${ }^{1}$, R. Denisova ${ }^{1}$, A. Mamutova ${ }^{1}$, A. Fetisova ${ }^{1}$, M. Gautier ${ }^{1}$ E. Krekhova ${ }^{2}$, M. Shingarova ${ }^{2}$, I. Kriulin ${ }^{1,2}$, A. Kontorovich ${ }^{1}$, O. Galkina $^{2}$, T. Radygina ${ }^{1}$, I. Zubkova ${ }^{1}$, N. Tkachenko ${ }^{1}$, Y. Orlova ${ }^{1}$, M. Kurdup ${ }^{1}$, A. Ismailova ${ }^{1}$, A. Alshevskaya ${ }^{3}$, A. Moskalev ${ }^{3}$, O. Lomakina ${ }^{1} .{ }^{1}$ National Medical Research Center of Children's Health, Moscow, Russian Federation; ${ }^{2}$ Sechenov First Moscow State Medical University (Sechenov University), Moscow, Russian Federation; ${ }^{3}$ Biostatistics and Clinical Trials Center, Novosibirsk, Russian Federation

Background: The need for continuous use of immunosuppressive drugs leads to increased risk of developing infectious diseases in children with juvenile idiopathic arthritis with systemic manifestation (sJIA). Questions about choosing the optimal vaccination time and the effect of different classes of therapy on vaccination effectiveness are still open.

Objectives: To study clinical and laboratory effectiveness of PCV13-vaccination in children with SJIA on tocilizumab (TOC) and canakinumab (CAN) treatment depending on disease activity stage.

Methods: Prospective cohort study included 2 groups of sJIA patients: in stable remission (Remission group, $n=53)$ receiving CAN $(n=10)$ or TOC $(n=43)$ treatment, and in acute stage of disease (Acute group, $n=25$ ) which started to received CAN $(n=7)$ or TOC $(n=18)$ either before vaccination (Acute Treated Before subgroup, $n=17$ ) or after vaccination (Acute Treated After subgroup, $n=8$ ). $0.5 \mathrm{ml}$ of the 13-valent PCV was administered once subcutaneously. Efficacy was evaluated by achieving of protection level of anti-pneumococcal antibodies after 4 weeks and by clinical indicators after 6 month follow-up: frequency of acute respiratory infections, frequency of antibiotics treatment courses, frequency of temporary withdrawal of biologics treatment due to severe infections. Frequency of events were counted per patients-years.

Results: Four weeks after vaccination, protection level of anti-pneumococcal antibodies was achieved by for $36(67.9 \%)$ patients in Remission group, $16(64 \%)$ patients in Acute group (intergroup $p=0.932$ ), and in $8(47.06 \%)$ patients in Acute Treated Before subgroup and in $8(100 \%)$ patients in Acute Treated After subgroup (intersubgroup $p=0.022$ ). $P C V 13$ have shown high clinical effectiveness in both Remission group and Acute group. Reducing of acute respiratory infections frequency was as follows: from 4.57 to 2.15 episodes per patient-year in Remission group $(p<0.001)$ and from 4.32 to 1.28 per patient-year in Acute group $(p<0.001)$. Duration of antibiotics treatment reduced from 2.31 to 0.81 weeks per 1 patient-year in Remission group $(p<0.001)$ from 1.97 to 0.74 in Acute group $(p<0.001)$. Among patients who were previously treated with biologics, frequency of therapy withdrawal reduced from 4.34 to 2.42 per patient-year in Remission group $(p<0.001)$ and from 3.53 to 1.18 in Acute Treated Before subgroup $(p=0.002)$. The incidence of reactions to vaccination of PCV13 (local hyperemia, pain, subfebrile temperature) was similar in groups $(22(41.5 \%)$ for Remission group and $7(28 \%)$ for Acute group, $p=0.319)$. Conclusion: Vaccination with the 13-valent PCV has demonstrated high clinical efficacy and safety in children with sJIA both in the acute stage of the disease and during remission. Vaccination of patients in acute stage of SJIA before treatment has advantages over vaccination during remission or after prolonged immunosuppressive therapy in terms of achieving an adequate vaccine response.

Disclosure of Interests: Dariya Vankova: None declared, Ekaterina Alexeeva Grant/research support from: Roche, Pfizer, Centocor, Novartis, Speakers bureau: Roche, Novartis, Pfizer., Tatyana Dvoryakovskaya: None declared, Ksenia Isaeva: None declared, Aleksandra Chomakhidze: None declared, Rina Denisova: None declared, Anna Mamutova: None declared, Anna Fetisova: None declared, Marina Gautier: None declared, Elizaveta Krekhova: None declared, Meyri Shingarova: None declared, Ivan Kriulin: None declared, Anastasiya Kontorovich: None declared, Olga Galkina: None declared, Tatyana Radygina: None declared, Irina Zubkova: None declared, Natalia Tkachenko: None declared, Yanina Orlova: None declared, Mariya Kurdup: None declared, Anna Ismailova: None declared, Alina Alshevskaya: None declared, Andrey Moskalev: None declared, Olga Lomakina: None declared

DOI: 10.1136/annrheumdis-2020-eular.5749

FRI0459

\section{TOFACITINIB TREATMENT IN RECALCITRANT JDM} PATIENTS

Ş. Çekiç ${ }^{1}$, Y. Karalii ${ }^{1}$ F. Cicek ${ }^{1}$, S. S. Kilic ${ }^{1} .{ }^{1}$ Uludag University Faculty of Medicine, Bursa, Turkey 